\title{
REVISION OF PASCH'S GEOMETRY
}

Vorlesungen über neuere Geometrie. By Moritz Pasch. Second edition. With an appendix: Die Grundlegung der Geometrie in historischer Entwicklung by Max Dehn. (Die Grundlehren der mathematischen Wissenschaften, Band 23.) Berlin, Springer, 1926. $\mathrm{x}+275 \mathrm{pp}$.

In 1882, Pasch's Vorlesungen über neuere Geometrie inaugurated a new era in the development of projective geometry. For the first time, projective geometry was made a purely deductive science founded upon and logically developed from a complete system of postulates. At the same time, since the postulates completely ignored the concept of parallelism, it was definitely made independent of euclidean or any metric geometry. This was in accord with a previous discovery by Klein that the theorems of projective geometry are independent of the parallel postulate.

The book was reprinted in 1912 with a short appendix and in 1913 it was translated into Spanish and the appendix of the 1912 edition was distributed over the book as smaller appendices at the ends of different sections.

The second edition just published follows the plan of the Spanish edition. The portion revised is not extensive. The rewritten material totals about two pages in the second edition and takes the place of about five pages of the first edition. It consists almost entirely of simplified proofs. In one place (page 47 , second paragraph) a proof that had covered two pages is now given in one short paragraph.

The second edition contains a total of eight pages of added material. This is inserted piecemeal as supplements to the various sections or as isolated paragraphs between two formerly adjacent paragraphs. Some new theorems are added, for example: p. 7, Kernsatz IX; p. 25, Lehrsätze $13,14,15$; p. 39 , theorem by Ventura Reyes y Prosper; p. 76, Sätze J and P. Aside from these, the supplementary material consists mainly of comments and references.

The typographical errors of the first edition are corrected. This was not done in the reprint of 1912 .

The evident desire to supplement rather than revise this important pioneer work is best explained by the author himself in his preface to the second edition. After discussing some of the more recent methods and results, he continues, "I do not desire to incorporate these new geometric concepts in the new edition, but prefer to keep the point of view of the first edition. If the reader will allow himself to be carried back in imagination for half a century, he may wish at least to acquaint himself with the geometry of that period and with the position this book had in its time in the foundations of geometry."

As the preferable alternative to enlarging and revising his own book so as to include the new concepts, Pasch requested Dehn to write an appendix covering this field. The last eighty-seven pages of the book 
comprise this appendix which, as stated in the preface, corresponds to a two-hour semester course of lectures given by the author.

In the introduction, the development of the investigations in the foundations of geometry is divided into four periods:

1. The parallel postulate of Euclid.

2. The continuity postulate of Archimedes.

3. Projective geometry.

4. The modern period in which the foundations of geometry have been studied as such. This period began with the work of Lobatchewsky in 1826.

The first chapter gives a rapid survey of the attempts to prove the euclidean parallel postulate, the new geometrical concepts that were initiated by these attempts, and especially the development of these concepts from the time of Lobatchewsky to that of Pasch.

The four remaining chapters follow closely in content and method the work of Hilbert contained in his Grundlagen der Geometrie (1899) and in a later memoir in the Mathematische Annalen (1903). Many references to Hilbert assign to him the authorship of the major portion of these chapters. More recent authors are also frequently cited, but most of these citations refer to new derivations or extensions of Hilbert's results. Some of these extensions were made by Dehn himself, notably his work in pseudogeometry and non-Archimedean geometry.

The contributions of certain other geometers, particularly E. H. Moore and Veblen, should have had a place in this supplement. The findings of E. H. Moore that some of Hilbert's axioms are redundant and that Schur's statement concerning the redundance of certain others is incorrect are especially pertinent.

Some interesting new features are: The serviceable table on page 229 shows distinctly the interrelations of various basic theorems of projective geometry. The extended principle of duality is proved (pp. 237-239) to be a direct consequence of the commutative law for the multiplication of line segments. The euclidean parallel postulate and the Archimedean postulate of continuity are shown to have a projective property in common (pp. 247-248).

The appendix is ably written and well worth reading. Only the work of Hilbert is given in detail, but most of the principal European geometers are cited. The author has succeeded remarkably well in presenting such an extensive subject so briefly.

It is peculiarly fitting that these two contributions to the foundations of geometry should be bound in one volume--the classical work of Pasch, reëdited after a half century by himself and the great work of Hilbert, rewritten, extended at times and revised somewhat in methods of presentation and proof by one of his former students who was with him when these concepts were taking form.

T. R. HOLLCROFT 